\title{
Mechanical Analysis of Crossbeam in a Gantry Machine Tool and its Deformation Compensation
}

\author{
Li Qilong ${ }^{*}, 1$, Guo Xuhong ${ }^{1}$, Chen Yao ${ }^{1}$, Ji Wenzheng ${ }^{2}$, Wang Liang ${ }^{1}$ and Zhang Tao ${ }^{1}$ \\ ${ }^{1}$ College of Mechanical and Electric Engineering, Soochow University, Suzhou, Jiangsu 215006, P.R. China \\ ${ }^{2}$ Jiang Yuan Precision Machinery Co. Ltd, Suzhou, Jiangsu 215006, P.R. China
}

\begin{abstract}
The beam is an important component in agantry machining center, and its deformation is believed to have asignificant impact on both the machining accuracy and the machining performance. In this research, the finite element models of a complete gantry machining center and the crossbeam are established, in whicht he restraint and boundary conditions for the finite element analysis are also introduced. It is noted thatthe impact of balance cylinders on the key components is fully considered when dealing with the force analysis. Computed results of the static characteristic analysis showed that the maximum deformation is about $0.080925 \mathrm{~mm}$ when crossbeam operates under different conditions. Then, the distortion curve and the compensation curve of guide rail are obtained, and the equation of a fitting compensation curve is also deduced through numerical analysis. This research is expected to provide a theoretical guide for distortion compensation of the crossbeam.
\end{abstract}

Keywords: Beam, Deformation compensation, Guide, Mechanical analysis.

\section{INTRODUCTION}

With the rapid development of engineering machinery, rail transportation, aerospace, energy and other industries, large and heavy machinery parts are largely used in key equipment manufacturing products. Gantry machine which is the main tool to process large, heavy parts plays a significant role in the field of heavy equipment manufacturing [1]. As a gantry machine 's main supports, beam plays an extremely important role in the dynamic and static characteristics. Deformation of beam and rail has an impact on machining accuracy. Thereby, the machine's performance is affected. So study the static properties and deformation of beams is of great significance for improving the machining accuracy and efficiency of the machine.

In recent years, the machine beams were deeply studied by many domestic universities and research institutions. Li Boji et $a l$, by using the finite element software, analyzed deformation of the beam from the aspect of the structure design and explained the influence of manufacturing process on the beam deformation [2]. Guan Yingjun et al. who established beams finite element model of the beams of a mobile gantry machining center and analyzed its static and dynamic stiffness. Finally they proposed optimization solution [3]. Li Yan et al. who used the finite element analysis technology to analyze static characteristic of machine and the main components found that the beams and ram were the weak link which affected the overall static stiffness. The structure of beam and ram were improved and the static stiffness of machine increased [4]. Hou Hongling

*Address correspondence to this author at the College of Mechanical and Electric Engineering, Soochow University, Suzhou 215006, China; Tel: 18896582789; E-mail: 18896582789@163.com et al. who used the finite element analysis software, under similar material and cross-sectional dimensions of space, analyzed static and modal charactersistic for the beams of several structures of the cross-sectional different shapes. Through the research on the structural deformation and the first-order frequency comparison, initially the reasonable beam structure is determined [5].

Although a series of studies on beam static and dynamic characteristics were studied by domestic scholars, they just discuss that beam structure has an impact on its deformation. Because weight of heavy machine increased drive motor power and the burden of the screw, so the balance cylinders which are installed on the vertical moving parts can balance structure's own gravity. The impact that balance cylinders have on the key components is fully considered. To improve the machine $\mathrm{X}$-axis' and $\mathrm{Z}$ axis' movement accuracy, and machining precision, stability and increase in component life are of great significance [6].

\section{XH2130 GANTRY MACHINING CENTER BRIEF INTRODUCTION}

XH2130 gantry machining center consists of bed, table, column, fixed beams, moving beams, slide, ram, Annex head library, magazine, hydraulic systems, lubrication systems, electrical systems and other components. It is portal gantry machine with moving crossrail that obtains good rigidity. Fig. (1) shows X2130 gantry machining center's brief introduction.

Beam and ram hydraulic automatic balancing systems are of great significance to improve the machining accuracy, speed, stability and increase component's life. Its function is that the weight of the beam and ram are balanced out by the hydraulic system. In a variety of conditions, it reduces 


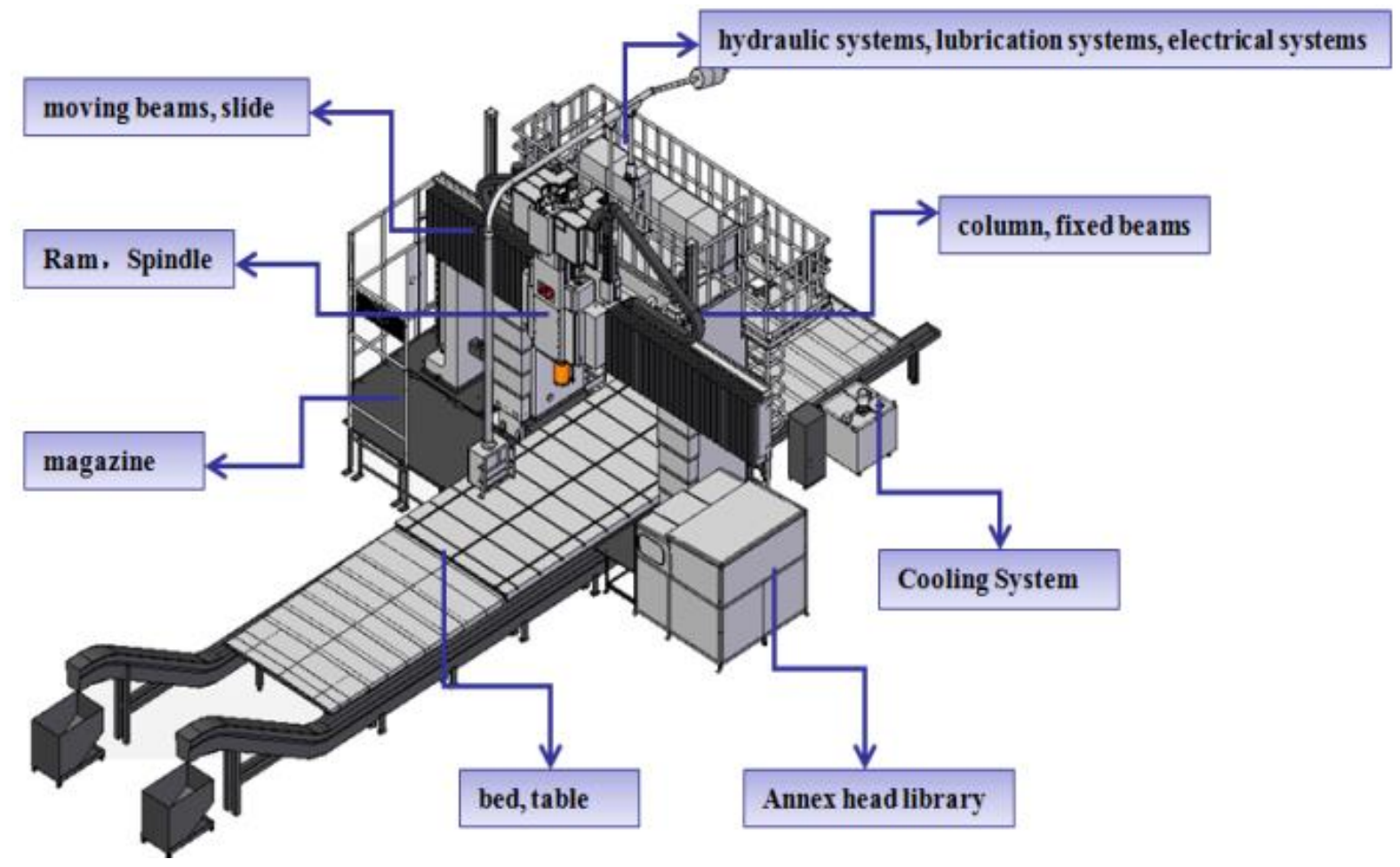

Fig. (1). Introduction of X2130 gantry machining center.

unwanted movement of the servo motor and the beam deflection. Thus maintains the movement accuracy of the beam.

Machine coordinates are defined as follows: $\mathrm{X}$-axis: the table reciprocates along the rail bed; $\mathrm{Y}$-axis: slide reciprocates along the beam's rails; Z-axis: ram reciprocates along the slide's rails; W-axis: the beam reciprocates along the column's guide [6].

When the finite element model is calculated, $\mathrm{X}$ direction is the direction of movement of the slide. Y direction is not only the positive direction of movement of the ram, but also the direction of the acceleration of gravity, and $\mathrm{Z}$ direction is the direction of the moving table. The coordinate system defined is different from the machine coordinate. Therefore, in the following section of this article, unless otherwise specified, the $\mathrm{X}$ direction, $\mathrm{Y}$ direction and $\mathrm{Z}$ direction refer to the finite element model and the calculation results. The $X$ axis, $\mathrm{Y}$ axis and $\mathrm{Z}$ axis refer to the machine coordinates. It is used to represent the position of the movement of each machine's structure.

\section{FINITE ELEMENT MODEL}

\subsection{Defining Material Properties and Meshing}

When modeling, the model is simplified. It can reduce the time of finite element meshing and improve the mesh quality, and then the ANSYS WORKBENCH software is imported, material properties are as followed in Table $\mathbf{1}$.

The method of mesh is Automatic. The size of mesh is Coarse. The result of meshing is shown in Fig. (2) [7].
Table 1. The Main Material Parameters.

\begin{tabular}{|c|c|c|c|}
\hline Material & $\begin{array}{c}\text { Elastic } \\
\text { Modulus (GPa) }\end{array}$ & $\begin{array}{c}\text { Density } \\
\text { (g/cm3) }\end{array}$ & $\begin{array}{c}\text { Poisson's } \\
\text { Ratio }\end{array}$ \\
\hline \hline HT300 & 130 & 7.35 & 0.270 \\
\hline QT600-3 & 169 & 7.12 & 0.286 \\
\hline Bearing & 280 & 7.82 & 0.300 \\
\hline
\end{tabular}

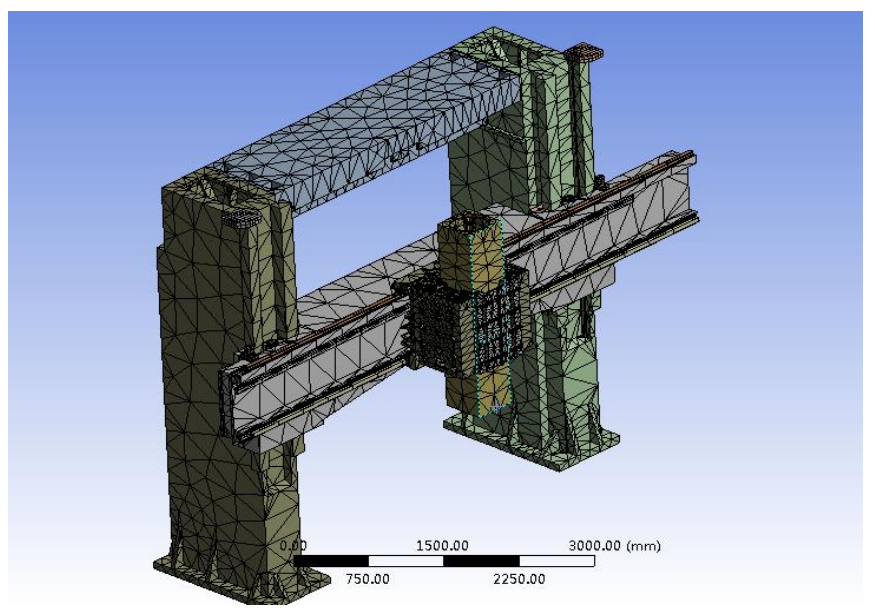

Fig. (2). The finite element mesh model.

\subsection{Constraints and Loading Conditions}

\subsubsection{Constraints}

(1) Machine column fixed on the ground, will be the two pillars of the ground set to a fixed constraint. Column connecting with the ground set to a fixed constraint; 
(2) The ball screw on the column drive beams to move up and down. The displacement of $Y$ direction of nut seat along the rail is constrained. The displacement of Y direction of ram's nut seat is constrained. The displacement of $\mathrm{X}$ direction of Slide's nut seat is constrained.

\subsubsection{The Forces}

(1) Gravity: Acceleration is set to the $\mathrm{Y}$ direction. The size is $9806.6 \mathrm{~mm} / \mathrm{s}^{2}$.

(2) Cutting Force: As the design parameters are known, the maximum cutting torque is $1200 \mathrm{Nm}$, the diameter of the cutting disc is $300 \mathrm{~mm}$. Therefore, the cutting force is: $1200 / 0.15=8000 \mathrm{~N}$.

(3) Discussing force conditions which increases the balance cylinder on the beams and the ram: Because its own weight of heavy machine has an influence on structural part, so the balance cylinders are installed on the vertical moving parts in order to reduce drive motor power and the burden of the screw.

Balance cylinders which are installed on moving beams are fixed on two columns. Using the trolley pull the moving beam's hanging blocks. Therefore, the reaction force acting on the column is not a simplified case. The sum of weight of all the parts on moving beams: moving beam's mass (9300 $\mathrm{kg})+$ slide's mass $(2220 \mathrm{~kg})+$ ram's mass $(2108 \mathrm{~kg})=13628$ $\mathrm{kg}$. The average of reaction force on each column is $66822 \mathrm{~N}$. The balance force on the moving beam's hanging block is $113570 \mathrm{~N}$. The average of reaction force on each hanging block is the $56785 \mathrm{~N}$.

Ram balancing cylinder is to overcome its own gravity of all parts which is on the ram. Two ram balancing cylinders are located on both sides of the ram, and fixed in the slide. The end of drawbars are fixed at the top of the ram. Pulling force on the ram is the simplified model's weight, which is 94849.8 $\mathrm{N}$. And the reaction force acting on the slider is the actual weight of the slide which is $20672 \mathrm{~N}$ [8]. Specific conditions and constraints of the force are shown in Fig. (3).

\subsection{Multi-Model Calculations}

Five key points are set for each structural movement in order to understand deformation of each structural part when they are moved to different positions. Five key points are located in the stroke to $0 \%, 25 \%, 50 \%, 75 \%$ and $100 \%$ position. Statistics are shown in Table $\mathbf{2}$.

\subsection{Static Analysis and Results}

Fig. (4) is the result of the deformation where slider's position is $\mathrm{Y}=2100 \mathrm{~mm}$, ram's position $\mathrm{Z}=1000 \mathrm{~mm}$, and moving beam's position is $\mathrm{W}=1200 \mathrm{~mm}$.

The maximum deformation is the position where the balancing cylinder on the moving beams connects with columns. The deformation has less impact on machining accuracy, but modifying the structure can be considered.

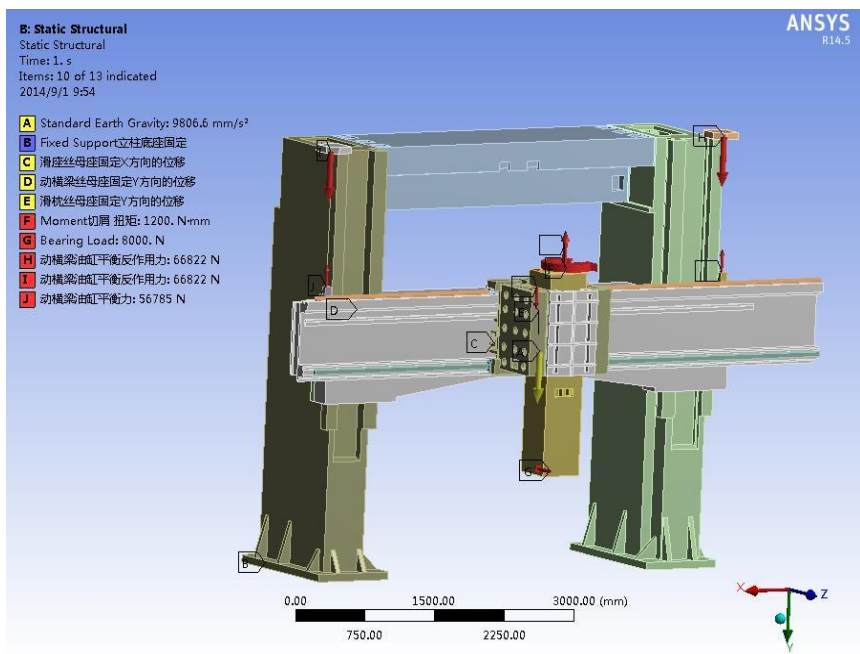

Fig. (3). Restriction and force loading.

Table 2. The stroke position for movable beam, ram and slide.

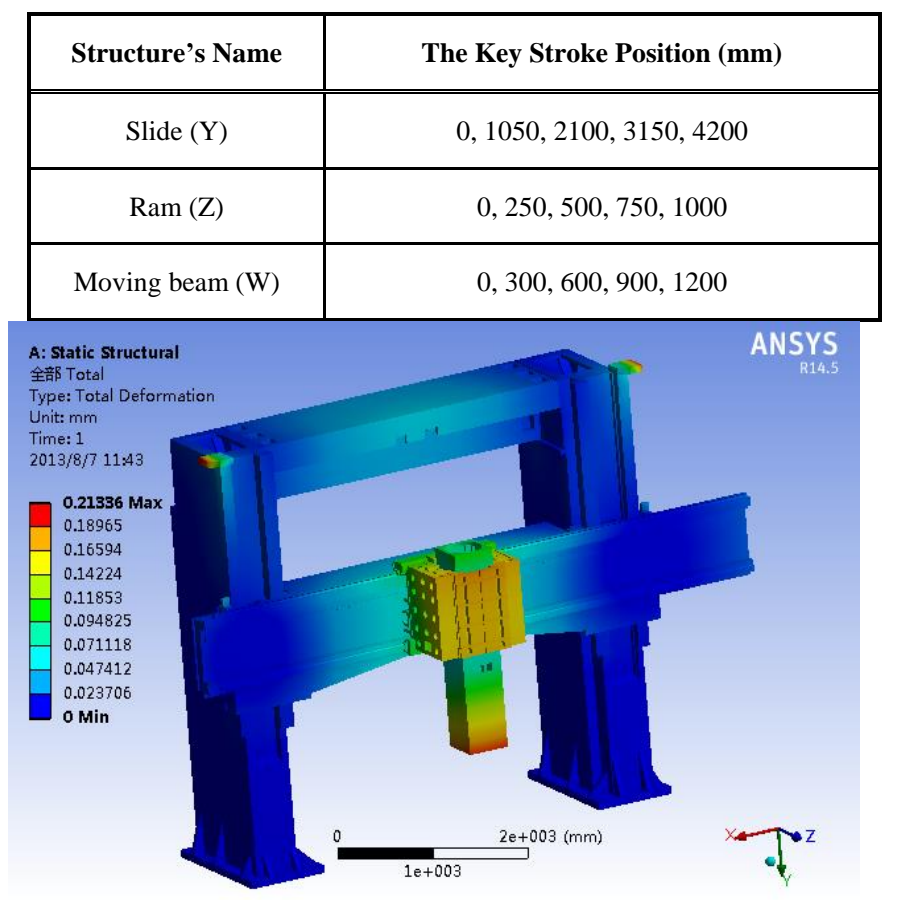

Fig. (4). Machine deformation for slide $Y=2100 \mathrm{~mm}$, ram $Z=1000$ $\mathrm{mm}$, moving beam $\mathrm{W}=1200 \mathrm{~mm}$.

After a multi-model calculation, beam's X, Y, Z and the total deformation are obtained. The data shows that changing beam and ram's position has less impact on the deformation of the beam. So this analysis focuses on what impact the position of slider has impact on the deformation of the beams. The specific situation is as follows.

1) When there is only gravity without cutting force, deformation is shown in Fig. (5):

2) When cutting force is $\mathrm{X}=-8000 \mathrm{~N}$, deformation is shown in Fig. (6). 


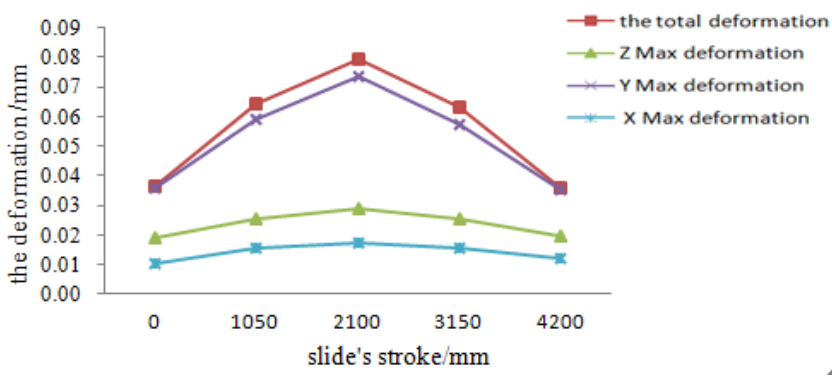

Fig. (5). Deformation of beams in $\mathrm{X}, \mathrm{Y}, \mathrm{Z}$ direction and their total with the sliding arranged at different positions.

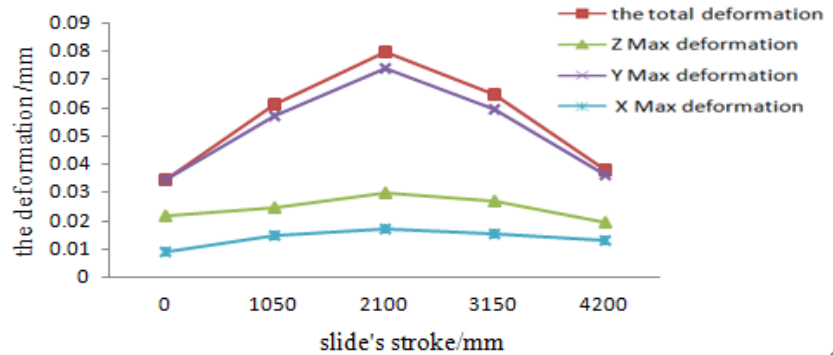

Fig. (6). Deformation of beams $X, Y, Z$ direction and their total with the sliding arranged at different positions.

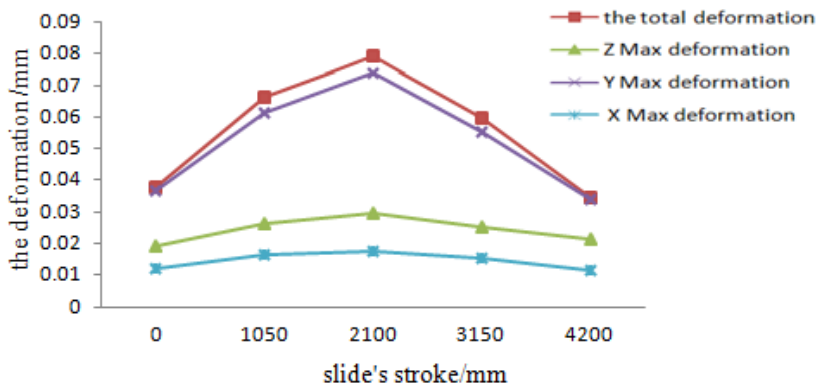

Fig. (7). Deformation of beams in $X, Y, Z$ direction and their total with the sliding arranged at different positions.

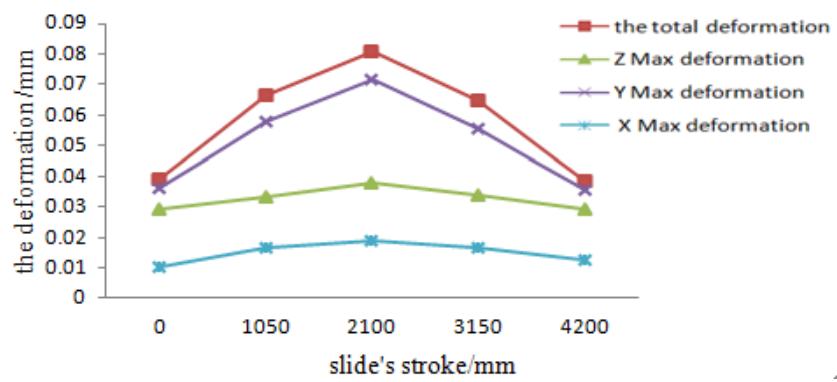

Fig. (8). Deformation of beams in $\mathrm{X}, \mathrm{Y}, \mathrm{Z}$ direction and their total with the sliding arranged at different positions.

3) When cutting force is $\mathrm{X}=+8000 \mathrm{~N}$, deformation is as shown in Fig. (7).

4) When cutting force is $\mathrm{Z}=+8000 \mathrm{~N}$, deformation is as shown in Fig. (8).

5) When cutting force is $\mathrm{Z}=-8000 \mathrm{~N}$, deformation is as shown in Fig. (9).

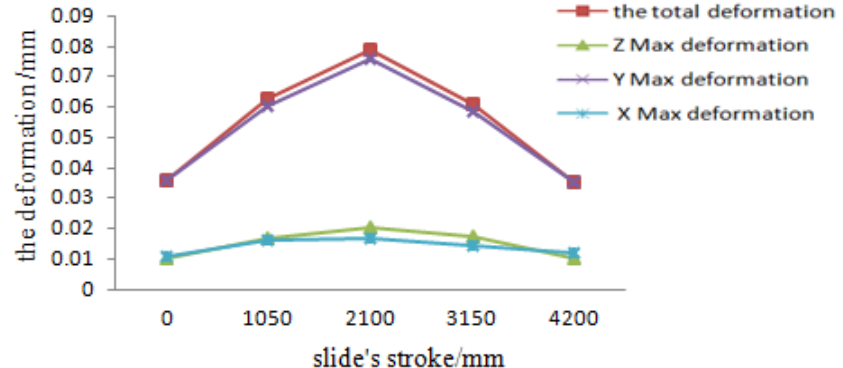

Fig. (9). Deformation of beams in $\mathrm{X}, \mathrm{Y}, \mathrm{Z}$ direction and their total with the sliding arranged at different positions.

By analyzing the above results, it can be seen that the amount of deformation of the beam in the $X$ direction and the $\mathrm{Z}$ direction is unchanged, and variety is small when the slide, beams and ram position changed. Y direction is deformation of the beam has a larger relationship with the slide stroke. Changes in the position between the beam and the ram position is small relationship. When the slide position is in the middle of the beam, the deformation of beam and Y directions are the maximum, and gradually decreases toward the ends. The maximum displacement is $0.08092539 \mathrm{~mm}$. Deformation analysis of ram shows that the larger ram stroke is, the greater the deformation is. The reason is that the ram extends out the slide so that it becomes a cantilever beam. When the cutting force acts at the end, the extending length of the cantilever beam is larger and the deformation is greater. In summary, the ram extending structure can be considered to amend, or add other auxiliary support structures to improve their rigidity.

\section{THE DEFORMATION OF BEAM'S RAIL AND COMPENSATION}

Considering actual working conditions of beams rail, finite element analysis model of rail is established. It is shown as Fig. (10). Two rail surfaces are marked on the rail and lower rail. The deformation of the two beams rail surface is analyzed, and the deformation curve of the rail is drawn. Deformation results of rail is as shown in Fig. (11).

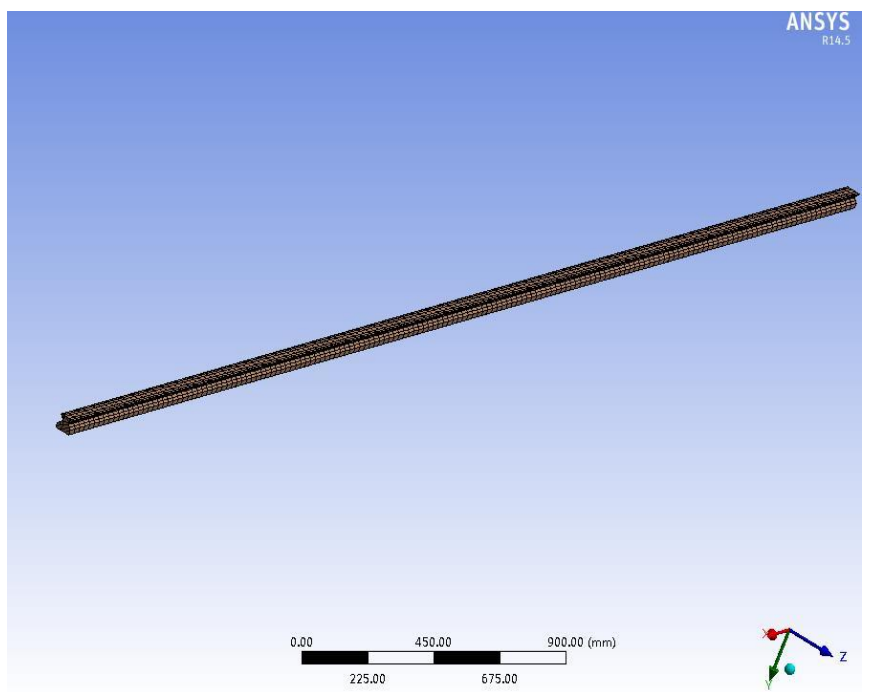

Fig. (10). The finite element model of guide. 


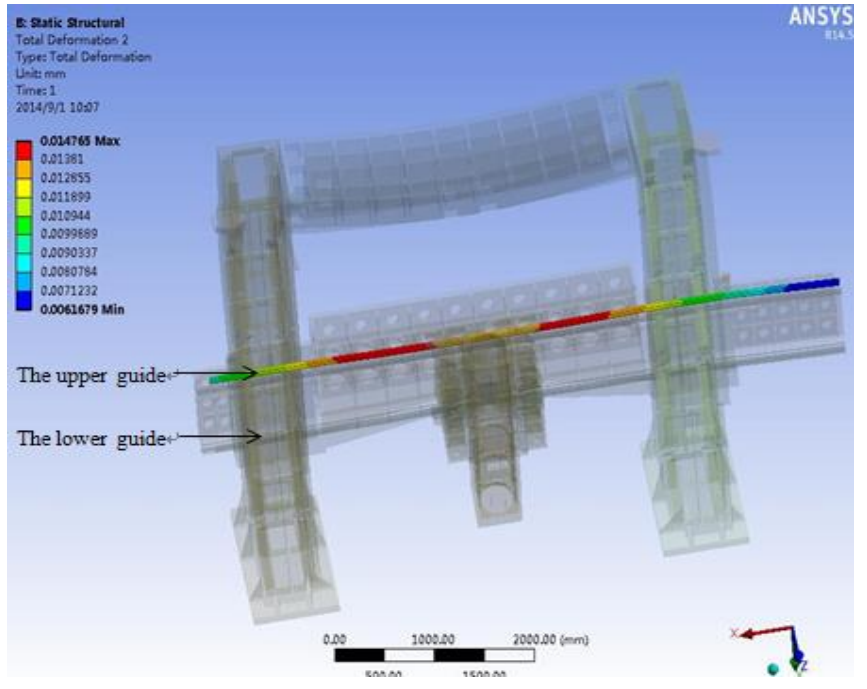

Fig. (11). Deformation of the upper guide.

The result shows that the trend is upward convex deformation when the upper and lower guide rails are in the forces. It is fully compliant with the stress analysis and actual deformation. According to the principle of compensation, compensation curve of the rail surface is drawn, in accordance with the compensation curve machining beams curved guide surface to compensate rail surface.

Because compensation curve is connected into a curve which is based on the series of points and does not follow rules, so in order to obtain curve equation of the compensation deformation of the rail, deformation curve needs to be fitted. By testing, the sixth-order polynomial fitting curve is the best, and gets compensation curve fitting equation as shown in Fig. (12).

Compensation curve fitting equation on the rails:

$Y_{1}=7 E-0.8 x^{6}-5 E-06 x^{5}+0.0001 x^{4}-0.0011 x^{3}+0.0047 x^{2}$

$-0.0091 \mathrm{x}-0.0318$

Compensation curve fitting equation on the lower rails:

$Y_{2}=5 E-0.8 x^{6}-4 E-06 x^{5}+8 E-05 x 4-0.0008 x^{3}-0.0027 x^{2}$ $0.0048 \mathrm{x}-0.0355$

Fitting degree is 0.9972 and 0.9965 . It is high degree and fitting success [9].

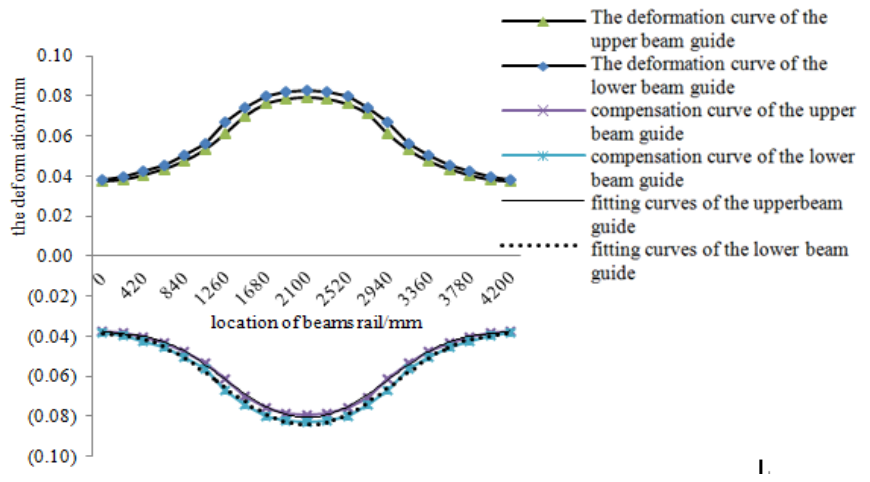

Fig. (12). Deformation curve and compensation curve of the crossbeam guide.

\section{CONCLUSION}

1. By analyzing the above results, it can be seen that the amount of deformation of the beam in the $X$ direction and the $\mathrm{Z}$ direction is unchanged, and variety is small when the slide, beams and ram position changed. Y direction's deformation of the beam has a larger relationship with the slide stroke. Changes in the position between the beam and the ram position has small relationship. When the slide position is in the middle of the beam, the deformation of beam and Y directions is the maximum, and gradually decreases toward the ends. The maximum displacement is $0.08092539 \mathrm{~mm}$. Deformation analysis of the ram shows that the larger ram stroke is, the greater the deformation is. The reason is that the ram extends out the slide so that it becomes a cantilever beam. When the cutting force acts at the end, the extending length of the cantilever beam is larger and the deformation is greater. In summary, the ram extending structure can be considered to amend, or add other auxiliary support structures to improve their rigidity.

2. The trend is upward convex deformation when the upper and lower guide rails are in the forces. It is fully compliant with the stress analysis and actual deformation. According to the principle of compensation, compensation curve of the rail surface is drawn, in accordance with the compensation curve machining beams curved guide surface to compensate rail surface. It will provide the theory reference for the crossbeam distortion compensation.

\section{ABOUT THE AUTHORS}

First Author Li Qilong, College of Mechanical and Electric Engineering, Soochow University. The author's major is finite element analysis and research of machine.

Second Author Guo Xuhong, Professor in Soochow University. The author's Scientific interest is cutting mechanism, precision finishing and optimization of process parameters. 40 papers and 2 patents had been published.

\section{CONFLICT OF INTEREST}

The authors confirm that this article content has no conflict of interest.

\section{ACKNOWLEDGEMENTS}

This work was financially supported by the transformation project of Jiangsu province results (BA2014004), Suzhou Application Foundation (SYG201234) and Jiangsu province IUR cooperative innovation Foundation (BY2014059-17).

\section{REFERENCES}

[1] X. Wang, Z. Jia, F. Yang, and S. Zhang, "The Topological Optimation Design and Analysis for Gantry Machine Tool Crossbeam Component," Manufacturing Technology \& Machine, vol. 59, no. 11, pp. 64-68, 2009.

[2] B. Li, Z. Feng, and q. Liang, "Deformation Analysis and Optimization for the Beam Rails of the Fix Beam Gantry Machine 
Center," Electrical Engineering Technology, vol. 40, no. 11, pp. 104-145, 2010.

[3] Y. Guan, D. Mu, Y. Zhao, and L. Ren, "Finite Element Analysis of GMCU2060 Gantry Machine Center Crossbeam," Machine Tool \& Hydraulics, vol. 39, no. 11, pp. 131-134, 2011.

[4] Y. LI, L. Zhang, C. Liu, and G. Yin, "Static Rigidity Analysis and Structure Optimization of 5-axis Gantry-type Machine Center," Modular Machine Tool \& Automatic Manufacturing Technique, vol. 53, no. 6, pp. 9-16, 2011.

[5] H. Hou, Z. Qiu, and Y. Zhao, "Static and dynamic analysis for beam of high-speed cutting machine tool," Mechanical Design and Manufacturing, vol. 44, no. 5, pp. 38-39, 2006.
[6] Y. Yu, "Research on the Hydraulic Automatic Balance System of the Milling Planer's Beam and Ram," Shenyang University of Technology, 2012.

[7] G. Ling, J. Ding, and Z. Wen, "ANSYS Workbench 13.0 from Entry to the Master," Version 2, Tsinghua University Press: Beijing, 2012, pp. 63-83.

[8] Y. Yuan, Y. Xu, and Y. Zhang, "ANSYS Workbench 14.0 Detailed Modeling and Simulation Techniques and Examples," Version 1, Chemical Industry Press: Beijing, 2014, pp. 137-141.

[9] L. Han, and K. Sun, "Anti-deformation processing gantry rail base and the EXCEL based COSMOSWORKS," World Manufacturing Engineering \& Market, vol. 25, no. 3, pp. 96-98, 2012.

() Qilong et al.; Licensee Bentham Open.

This is an open access article licensed under the terms of the Creative Commons Attribution Non-Commercial License (http://creativecommons.org/licenses/by-nc/3.0/) which permits unrestricted, non-commercial use, distribution and reproduction in any medium, provided the work is properly cited. 